\title{
ETHICAL CONSIDERATIONS IN TREATMENT AND RESEARCH IN SPINAL INJURIES
}

\author{
By Dr. H. L. Frankel \\ National Spinal Injuries Centre, Stoke Mandeville Hospital, Aylesbury, England
}

As specialists in spinal injuries we take our teaching on ethics from the main stream of medical opinion.

The portion of the Hippocratic Oath relevant to today's discussion in an English version is 'I will use treatment to help the sick according to my ability and judgement, but never with a view to injury or wrong-doing'. Medical ethics throughout the world were based to a greater or lesser extent on the Hippocratic Oath, depending on local customs.

Following World War II and the Nüremberg War Crimes Commission, the World Health Organisation set up a commission in Paris in 1947 which was extended and became the Declaration of Geneva I948 (fig. I). This is very similar to the Hippocratic Oath and is of a very general nature.

\section{DECLARATION OF GENEVA ${ }^{1}$}

\footnotetext{
'At the time of being admitted as a member of the Medical Profession:

I solemnly pledge myself to consecrate my life to the service of humanity.

I will give to my teachers the respect and gratitude which is their due;

I will practise my profession with conscience and dignity;

The health of my patient will be my first consideration;

I will respect the secrets which are confided to me;

I will maintain by all the means in my power, the honour and the noble

traditions of the medical profession;

My colleagues will be my brothers;

I will not permit considerations of religion, nationality, race, party politics or social standing to intervene between my duty and my patient;

I will maintain the utmost respect for human life, from the time of conception; even under threat, I will not use my medical knowledge contrary to the laws of humanity.

I make these promises solemnly, freely and upon my honour.'

${ }^{1}$ Adopted by the General Assembly of the World Medical Association at Geneva, Switzerland, September 1948.
}

Fig. 1

The Declaration of Helsinki 1964 (fig. 2) was also prepared by the World Health Organisation but was specifically concerned with research. Those parts that are specifically relevant for discussion are I. 3, I. 4, III. 3a, III. $3 \mathrm{~b}$ and III. 4a of the Declaration.

The Royal College of Physicians of London in 1967 and 1973 published guidance on the setting up of Ethics of Research Committees in Institutions:

Composition. To function efficiently ethical committees should be small and they must not be so constituted as to cause an unreasonable hindrance to the advancement of medical knowledge. The medical members should be experienced clinicians 
DECLARATION OF HELSINKI

It is the mission of the doctor to safeguard the health of the people. His knowledge and conscience are dedicated to the fulfilment of this mission.

The Declaration of Geneva of the World Medical Association binds the doctor with the words. "The health of my patient will be my first consideration'; and the Intermy patient will be my first consideration'; and the International Code of Medical Ethics which declares that 'Any
act or advice which could weaken physical or mental resistance of a human being may be used only in his interest."

Because it is essential that the results of laboratory experiments be applied to human beings to further scientific knowledge and to help suffering humanity, the World Medical Association has prepared the following recommendations as a guide to each doctor in clinical research. It must be stressed that the standards as drafted are only a guide to physicians all over the world. Doctors are not relieved from criminal, civil, and ethical responsibilities relieved from criminal, civil, and ethical

In the field of clinical research a fundamental distinction In the field of clinical research a fundamental distinction
must be recognised between clinical research in which the must be recognised between clinical research in which the
aim is essentially therapeutic for a patient, and clinical aim is essentially therapeutic for a patient, and clinical
research the essential object of which is purely scientific research the essential object of which is purely scientific
and without therapeutic value to the person subjected to the research.

\section{Basic Principles}

1. Clinical research must conform to the moral and scientific principles that justify medical research, and should be based on laboratory and animal experiments or other scientifically established facts.

2 . Clinical research should be conducted only by scientifically qualified persons and under the supervision of a qualified medical man.

3. Clinical research cannot legitimately be carried out unless the importance of the objective is in proportion to the inherent risk to the subject.

4. Every clinical research project should be preceded by careful assessment of inherent risks in comparison to foreseeable benefits to the subject or to others.

5. Special caution should be exercised by the doctor in performing clinical research in which the personality of the subject is liable to be altered by drugs or experimental procedure.
II. Clinical Research Combined with Professional Care

1. In the treatment of the sick person the doctor must be free to use a new therapeutic measure if in his judgement it offers hope of saving life, re-establishing health, or alleviating suffering.

If at all possible, consistent with patient psychology, the doctor should obtain the patient's freely given consent after the patient has been given a full explanation. In case of legal incapacity consent should also be procured from the legal guardian; in case of physical incapacity the perthe legal guardian; in case of physical incapacity the per2 . The doctor can combine clinical research with professional care, the objective being the acquisition of new medical knowledge, only to the extent that clinical research is justified by its therapeutic value for the patient.

III. Non-therapeutic Clinical Research

1. In the purely scientific application of clinical research carried out on a human being it is the duty of the doctor to remain the protector of the life and health of that person on whom clinical research is being carried out.

2 . The nature, the purpose, and the risk of clinical research must be explained to the subject by the doctor.

3a. Clinical research on a human being cannot be undertaken without his free consent, after he has been fully informed; if he is legally incompetent the consent of the legal guardian should be procured.

$3 \mathrm{~b}$. The subject of clinical research should be in such a mental, physical, and legal state as to be able to exercise mental, physical, and legal

3 c. Consent should as a rule be obtained in writing. However, the responsibility for clinical research always However, the responsibility for clinical research always
remains with the research worker; it never falls on the remains with the research worker; it
subject, even after consent is obtained.

$4 \mathrm{a}$. The investigator must respect the right of each individual to safeguard his personal integrity, especially if the subject is in a dependent relationship to the investigator. $4 \mathrm{~b}$. At any time during the course of clinical research the subject or his guardian should be free to withdraw permission for research to be continued. The investigator or the investigating team should discontinue the research if in his or their judgement it may, if continued, be harmful to the individual.

Fig. 2

with a knowledge of clinical research investigation and in addition there should be a lay member. cedures.

They gave particular emphasis to the patients being fully informed of pro-

Patients. Whenever the research investigation is not expected or is not intended to benefit the individual, a full explanation of the proposed procedure should be given and the patient must feel completely free to decline to participate or to withdraw at any stage.

Where the research is intended to benefit the patient, although consent should ordinarily be sought, there are sometimes circumstances in which it is inappropriate or even inhumane to explain the details and seek consent. Ethical committees should examine such cases with particular care.

In the Aylesbury area such a committee has been in existence for five years. Its membership currently consists of one doctor, from each of the divisions of medicine, surgery, psychiatry, spinal injuries and pathology, plus the medical records officer and a layman. All planned research projects are submitted to that committee for its approval in the first instance. In addition to seeing the details of the research project the committee asks for a special form to be filled in (fig. 3 ).

With this information the committee are easily able to reach a satisfactory decision. I would emphasise that all material submitted to this committee is 
Research Project for consideration by Ethics of Research Sub-Committee

(To be sent to Secretary of Ethics of Research Sub-Committee accompanied by copy of Protocol or Memorandum)

1. Project submitted by

2. Names of medical or other staff involved (Please indicate if not a member of hospital staff):

3. Brief description of project:

4. Describe the degree (if any) of:

(a) Danger of untoward effects:

(b) Discomfort:

(c) Pain:

(d) Embarrassment:

(e) Distress:

5. If new drugs are involved has the Dunlop Committee been informed?

Has clearance been obtained?

6. Are patients participating voluntarily and freely?

7. Have patients been informed that they are participating in a research project?

8. And that they may withdraw at any time?

9. State what consent has been obtained:

10. Remarks of assistance to Ethics of Research Sub-Committee:

Please note: (a) Consent will be given to the Consultant named above and is not transferrable from one project to another or from one person to another. (b) Variations from the original project, or alterations, in the direction of research will need to be submitted to the Ethics of Research Sub-Committee. (c) Untoward. events, complications and complaints (if any) relating to research should be notified to the Ethics of Research Sub-Committee.

Fig. 3

totally confidential. As this is a local committee and all the members are known and trusted by their colleagues, research workers need have no fear that their best ideas will be stolen before they have even started their work!

The position regarding research on our patients involving their medical records is quite clearly defined and in most cases the very existence of a committee has 
meant that the planned research has been prepared in an acceptable way. The Aylesbury committee has never had to reject any project: some have been modified after discussion. It is interesting that the main source of difficulty has been on matters of patient confidentiality when outside workers wanted to examine our patient's records.

How does this apply to our everyday work? After all, every attempt to treat a patient is an experiment; this is particularly true of the immediate treatment of spinal injury and the management of the urinary tract in incomplete paraplegia. We can only treat our patients adequately if we are well informed of the relative merits of the available treatments and have the knowledge of what is the natural history of a condition without treatment. In order to make proper use of the information we acquire in our everyday treatment, it is incumbent on us to keep accurate and adequate records.

I therefore maintain that it is the duty of all of us whether or not we are scientifically orientated to pursue clinical research. By this means we need not all repeat our mistakes again and again. We will also learn how to understand and evaluate research published by others. For these reasons I believe that for doctors practising our speciality of spinal injuries it is unethical not to pursue clinical research.

The Medical Research Council in 1964, giving guidance on responsibilities of investigations on human subjects commented:

So specialised has medical knowledge now become that the profession in general can rarely deal adequately with individual problems. In regard to any particular type of investigation. only a small group of experienced men who have specialised in this branch of knowledge are likely to be competent to pass an opinion on the justification for undertaking any particular procedure. But in every branch of medicine, specialised scientific societies exist. It is upon these that the profession in general must mainly rely for the creation and maintenance of that body of precedents which shall guide individual investigators in case of doubt, and for the critical discussion of the communications presented to them on which the formation of the necessary climate of opinion depends. Finally, it is the Council's opinion that any account of investigations on human subjects should make clear that the appropriate requirements have been fulfilled, and, further that no paper should be accepted for publication if there are any doubts that such is the case.

It is in this respect that the International Medical Society of Paraplegia has special responsibilities both in formulating that climate of opinion and those precedents which can guide us and newcomers to our speciality. In our scientific meetings and in our journal Paraplegia we have the means by which this is being achieved.

\section{REFERENCES}

Declaration of Helsinki (1964). World Medical fournal, II, 28I.

Medical Research Council (1964). M.R.C. Annual Report, 1962/63. Cmnd. 2382 H.M.S.O. (reprinted together with the Declaration of Helsinki in the British Medical fournal I $964,2,177-178$ ).

Royal College of Physicians of London (1967) and (1973). Committee on the Supervision on the Ethics of Clinical Research Investigations in Institutions. 